\title{
An Alternative Method of Spatial Autocorrelation for Chlorophyll Detection in Water Bodies Using Remote Sensing
}

\author{
Tainá T. Guimarães ${ }^{1}$, Maurício R. Veronez ${ }^{1,2, *}$, Emilie C. Koste ${ }^{1}$, Luiz Gonzaga Jr. ${ }^{1,3}$, \\ Fabiane Bordin ${ }^{1}$, Leonardo C. Inocencio ${ }^{1}$, Ana Paula C. Larocca ${ }^{4}$, Marcelo Z. de Oliveira ${ }^{1}$, \\ Dalva C. Vitti ${ }^{5}$ and Frederico F. Mauad ${ }^{5}$
}

1 Advanced Visualization \& Geoinformatics Lab_VizLab, Unisinos University, São Leopoldo 93022-750, Brazil; tainat@edu.unisinos.br (T.T.G); emiliek@edu.unisinos.br (E.C.K.); lgonzaga@unisinos.br (L.G.J.); fabianebo@unisinos.br (F.B.); lcinocencio@unisinos.br (L.C.I.); marceloz@unisinos.br (M.Z.d.O.)

2 Graduate Programme in Geology, Unisinos University, São Leopoldo 93022-750, Brazil

3 Graduate Programme in Applied Computing, Unisinos University, São Leopoldo 93022-750, Brazil

4 Graduate Programme in Transportation Engineering, São Carlos Engineering School, University of São Paulo, São Paulo 93022-750, Brazil; larocca.ana@usp.br

5 Graduate Programme in Environmental Engineering Sciences, São Carlos Engineering School, University of São Paulo, São Leopoldo 93022-750, Brazil; dalva@sc.usp.br (D.C.V.); mauadffm@sc.usp.br (F.F.M.)

* Correspondence: veronez@unisinos.br; Tel.: +55-51-3591-1100 (ext.1619)

Academic Editor: Hector Malano

Received: 5 January 2017; Accepted: 1 March 2017; Published: 11 March 2017

\begin{abstract}
Additional measures of in situ water quality monitoring in natural environments can be obtained through remote sensing because certain elements in water modify its spectral behavior. One of the indicators of water quality is the presence of algae, and the aim of this study was to propose an alternative method for the quantification of chlorophyll in water by correlating spectral data, infrared images, and limnology data. The object of study was an artificial lake located at Unisinos University, São Leopoldo/RS, Brazil. The area has been mapped with a modified NGB (near infrared (N), green (G) and blue (B)) camera coupled to an unmanned aerial vehicle (UAV). From the orthorectified and georeferenced images, a modified normalized difference vegetation index (NDVImod) image has been generated. Additionally, 20 sampling points have been established on the lake. At these points, in situ spectral analysis with a spectroradiometer has been performed, and water samples have been collected for laboratory determination of chlorophyll concentrations. The correlation resulted in two models. The first model, based on the multivariate analysis of spectral data, and the second model, based on polynomial equations from NDVI, had coefficients of determination $\left(R^{2}\right)$ of 0.86 and 0.51 , respectively. This study confirmed the applicability of remote sensing for water resource management using UAVs, which can be characterized as a quick and easy methodology.
\end{abstract}

Keywords: lake; chlorophyll; normalized difference vegetation index (NDVI); spectral reflectance; space autocorrelation

\section{Introduction}

The impacts of human activities on continental ecosystems have a number of consequences, such as the deterioration of water quality and significant changes in the hydrological and biogeochemical cycles and biodiversity. This process of deterioration has economic and social impacts and, in some cases, creates permanent and irreversible changes in lakes, rivers, and artificial reservoirs [1]. 
Among the main factors causing the degradation of water resources are the discharge of untreated industrial wastewater and sewage, as well as the drainage of agricultural areas. Effluents generated from these human activities have a chemical composition different from water in its natural state, leading to a water enrichment process, especially concerning phosphorus and nitrogen. When the levels of these two nutrients in water bodies considerably increase, the composition of the water changes, resulting in the phenomenon of eutrophication and leading to excessive growth of algae and aquatic weeds on the water surface [2].

Eutrophication is considered one of the main water quality issues worldwide, affecting both freshwater and marine ecosystems [3]. The chlorophyll-a (Chl-a) concentration is an important indicator of the lake eutrophication process and serves as an index that presents correlation with physical-chemical properties of water [4].

The monitoring and evaluation of water quality are fundamental to the management of water bodies and the improvement of their quality. In situ measurements and the collection of water samples for further laboratory analysis are traditionally used to monitor water quality. Although such measurements are accurate to a point in time and space, they may become costly and time-consuming, as well as inadequate to observe temporal and spatial variations over a large area. Remote sensing tools can be used as complementary or alternative methods to this monitoring, being able to estimate water quality over a large area and provide spatial and temporal views of parameters that are not readily available from in situ measurements $[5,6]$.

Remote sensing of water resources is used to find differences and relations between the electromagnetic solar radiation reflected from water and some water quality parameters that modify its spectral properties, such as chlorophyll, suspended sediments, and organic matter. With multispectral and hyperspectral orbital, aerial, and ground level imagery, it is possible to study these parameters based on their spectral response in specific spectral bands. Typically, by analyzing a single indicator (or a set of them), it is possible to determine the impact of various pollutants on the water status [6,7].

Remote sensing images play an important role in the assessment of water quality and management, especially in lentic systems and water bodies under eutrophication processes by assessing the pigment chlorophyll, which changes the optical properties of water and is associated with increased primary productivity and eutrophication [8].

Regarding the use of remote sensing technologies in the study of aquatic environments, spectroscopy and unmanned aerial vehicle (UAV) imagery have been characterized as a new way to access the limnological characteristics of these locations. Various studies have been performed in this field using UAV for monitoring of aquatic vegetation [9,10], flood events [11], water pollution [12], morphological and hydraulic characterization [13], and the determination of chlorophyll concentration [14,15]. It is important to highlight that rare studies use UAVs to assess eutrophic inland waters, which reiterate the importance of the present study.

The remote sensing platforms can be categorized as satellite (spaceborne), airborne, unmanned aerial systems (UASs) and mobile/static (ground), since they are the most frequently used remote sensing systems [16]. UASs, most popularly known as UAVs or drones [17], have been seen as the new paradigm of aerial remote sensing and mapping for their high-resolution and low-cost characteristics [18]. The advance in technology made the miniaturization of optical sensors possible, such that they could be coupled to UAVs that are able to perform low-altitude flights with more frequency, facilitating the analysis and monitoring of small areas [19].

The use of UAVs enables the measurement and monitoring of environment aspects with desired spatial and temporal resolutions, even under adverse environmental conditions, such as cloud cover [20].

Regarding the use of spectroradiometers in applications involving the environment, studies emphasize this tool as one of the most modern instruments to aid in the control and monitoring of water, allowing the projection of scenarios for planning purposes, as well as the modeling of correlation functions and use of data for control, monitoring, and diagnostic purposes [21]. 
Spectra collected in situ and above the water surface through a spectroradiometer may reveal the optically active material present in water and be used as important raw data for the Chl-a remote sensing estimation model. Studies indicate that the spectral response obtained in the field is the collective response of Chl-a and other components/minerals of lake water. Because minerals and other components vary from lake to lake, the spectral bands suitable for Chl-a estimation also vary and should be selected for a model by comparing the estimated values with the measured values obtained from laboratory analysis [22,23].

Given the above, the aim of this study was to propose an alternative method for monitoring and estimating chlorophyll concentration in water through the correlation between spectral data, infrared images obtained by UAVs, and limnology data from laboratory analysis.

\section{Materials and Methods}

\subsection{Field Site}

The study area is located in the campus of the Unisinos University, São Leopoldo-RS, Brazil, and the study material is the largest lake present there, which has an area of approximately $25,000 \mathrm{~m}^{2}$ (Figure 1). The lake is an artificial water body, with maximum depth of $4 \mathrm{~m}$ in its central area. Occasionally, the lake also receives the drainage of rainwater, since it is located at the lowest portion of the terrain.

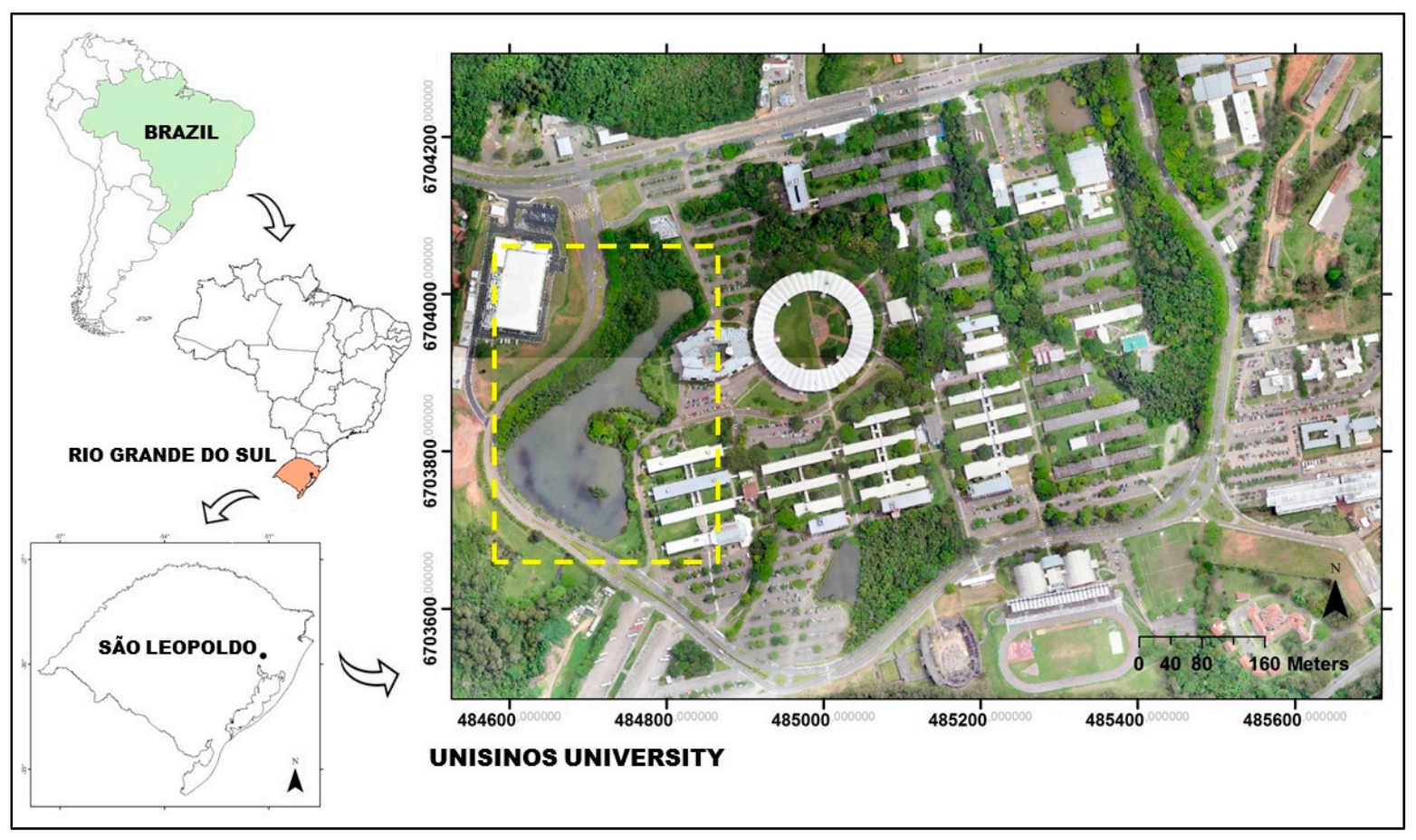

Figure 1. Study area location.

\subsection{Data Acquisition}

Field sampling for data acquisition was carried out in March 2016 and consisted in a UAV flight over the reservoir area and the in-situ collection of spectral data and water samples in 20 spatialized sampling points.

Figure 2 shows the position of the 20 sample points adopted in this study. 


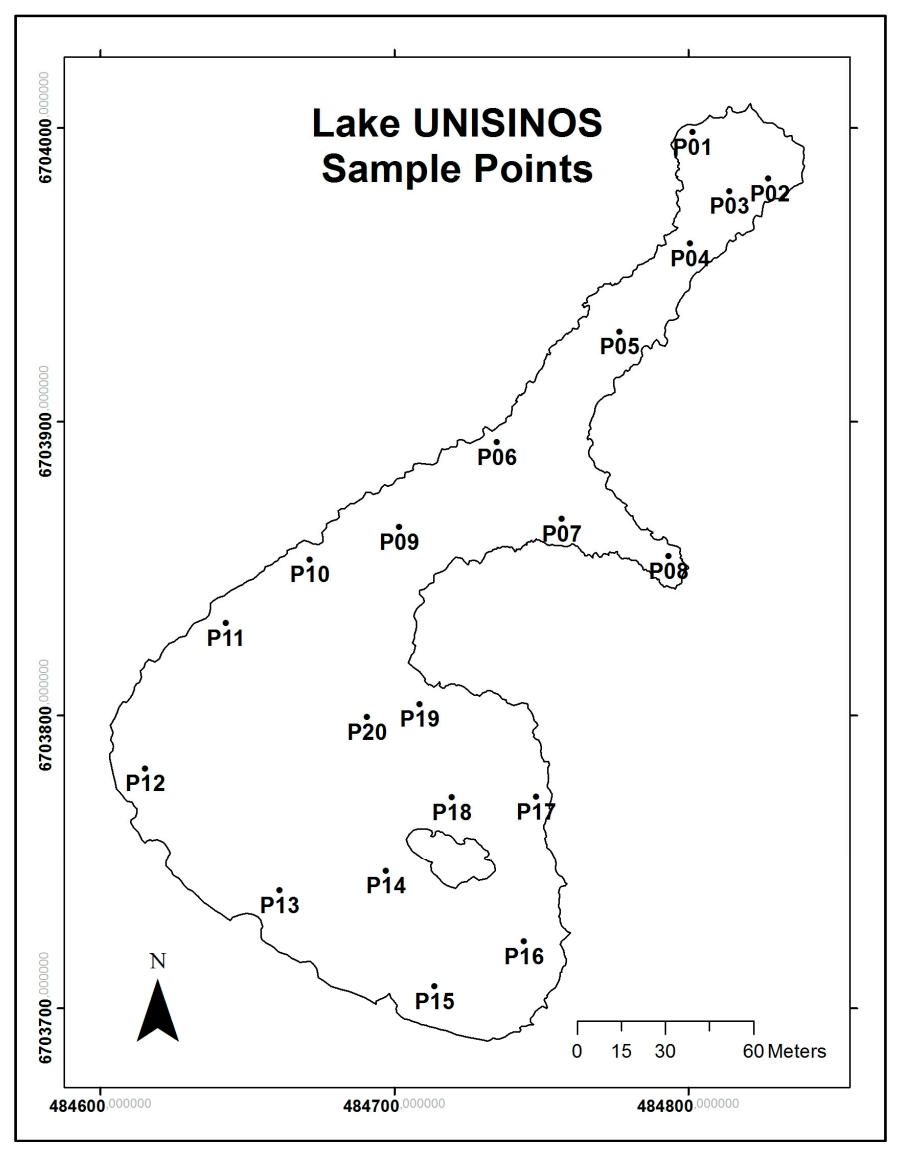

Figure 2. Position of the sample points adopted.

We collected the spectral response of the water using the spectroradiometer Spectral Evolution, model SR-3500, with a spectral range scan from 350 to $2500 \mathrm{~nm}$ and spectral resolution varying from 3.5 to $7.0 \mathrm{~nm}$. The adopted methodology was the spectral measurement of absolute reflectance. For the measurement, we used a lens with a $1^{\circ}$ target field, which has been coupled to the spectroradiometer, with a distance of approximately $1 \mathrm{~m}$ from the water surface at an angle of $90^{\circ}$. We explored only wavelengths between 400 and $900 \mathrm{~nm}$, which are characteristic of the COAs (Optically Active Compounds) present in water.

The UAVs used in the image acquisition was a fixed-wing SwingletCAM from SenseFly (Figure 3), which has been coupled with a camera capable of capturing 3 different channels: near infrared (NIR), green (G), and blue (B). The camera used was a Canon ELPH 110HS with 16 megapixels resolution, factory-modified to capture the NIR band instead of the red band. The flight was carried out at an altitude of $170 \mathrm{~m}$, obtaining 28 high-resolution images and resulting in a mapped area of approximately $250.000 \mathrm{~m}^{2}$.

In addition to the UAV survey, we collected 6 ground control points (GCPs) to ensure the positional accuracy of the cartographic products generated. The GCPs had their coordinates determined through a GNSS (Global Navigation Satellite System) system, using RTK (Real Time Kinematic) method and were distributed over the area homogeneously to avoid clustering distortions.

The images obtained by the UAV were later processed in the PIX4D software version 2.1 (Pix4D: Lausanne, Switzerland, 2016), where the images have been georeferenced and orthorectified. We adopted the SIRGAS 2000 (Geocentric Reference System for the Americas) as the reference system in UTM (Universal Transverse Mercator) projection, zone 22S.

The PIX4D software presents a simple workflow for UAV data processing in 3 steps. The first step creates a controlled mosaic and informs the accuracy of the model after applying the GCPs. The second 
step creates a point cloud from the images pixels using Image-Based Modeling technique. The third step transforms the point cloud into a Digital Surface Model (DSM) that is used as the basis for the orthorectification process.

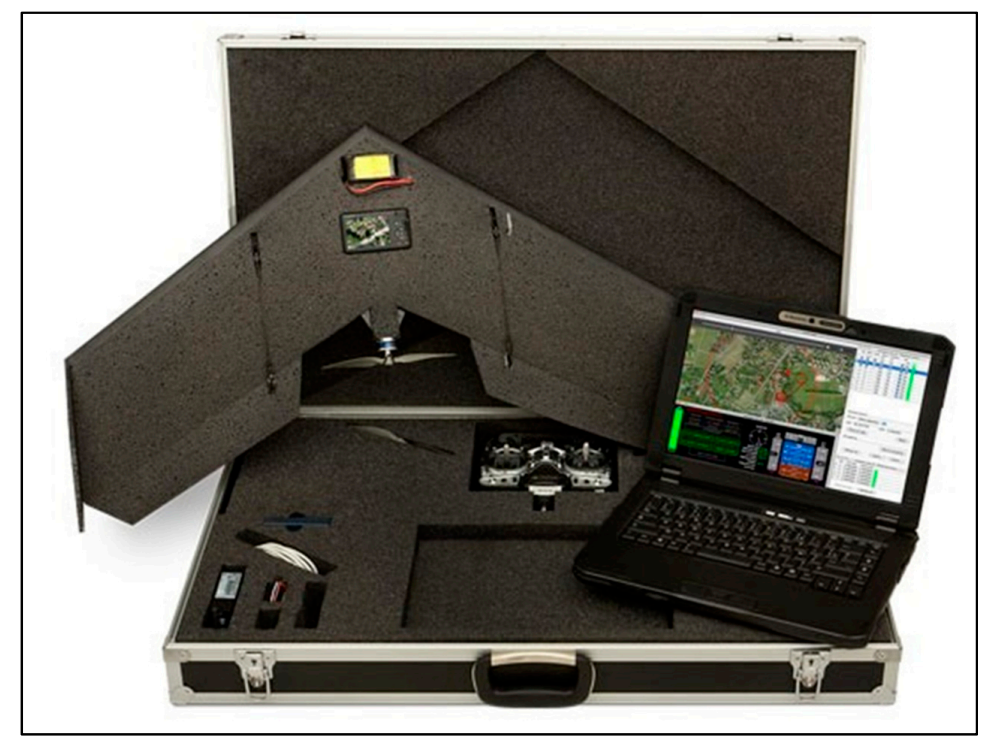

Figure 3. Swinglet CAM.

\subsection{Data Analysis}

With the water samples, we carried out the determination of the chlorophyll-a concentration using the spectrophotometric method proposed by Nusch [24].

During the processing of reflectance data collected in the field, some noisy data were identified in the dataset. As a preparatory step to analyze the spectral reflectance, the curves were softened by applying a data smoothing method called the moving average filter, in which we considered a window having a size of five points.

From the georeferenced orthophoto, we generated a modified normalized difference vegetation index (NDVI) (NDVImod) image for the entire flight coverage area from an adaptation of the index usually used, an NIR band instead of a red band, due the use of a modified IR camera. The equation used is shown below:

$$
N D V I m o d=\frac{(N I R-B)}{(N I R+B)}
$$

where NIR is the near infrared channel and $B$ refers to the blue channel.

In possession of all the proposed data (NDVImod image, spectral data and concentration of chlorophyll-a in the sampling points), the last step established a correlation between them to propose a mathematical model to quantify (or estimate) the chlorophyll-a present in the water. We conducted the study of these correlations by developing scatter plots, which returns a coefficient of determination $R^{2}$ on the trend between two variables (chlorophyll-a content and spectral or NDVImod results) as well the best applicable function that can explain this trend. In addition to these analyses of simple correlations between two variables, we also worked with multiple linear regressions, which consider the possibility of several independent variables in the system to explain a dependent variable (in this case, chlorophyll).

\section{Results and Discussion}

This section presents the results and discussions of this research, which are organized into three sub-sections: the results of the laboratory analysis, the correlation between NDVImod and 
chlorophyll values from spectral data, and the correlation between NDVImod and chlorophyll from UAV images.

\subsection{Results of the Laboratory Analysis}

The methodological procedures developed in the laboratory obtained satisfactory results as the determination of the chlorophyll-a concentration in the water samples collected in the field. The summary of the results is shown in Table 1.

Table 1. Summary of results for chlorophyll-a (Chl-a) analysis.

\begin{tabular}{cc}
\hline Parameter & Value $(\mu \mathrm{g} / \mathrm{L})$ \\
\hline Average & 150.98 \\
Minimum value/Location & $115.79 / \mathrm{P} 05$ \\
Maximum value/Location & $231.01 / \mathrm{P} 11$ \\
Standard deviation & 27.66 \\
\hline
\end{tabular}

\subsection{Correlation between Spectral Data and Chlorophyll}

The spectral responses collected in the sampling points, after going through the data smoothing process, are shown in the graph of Figure 4.

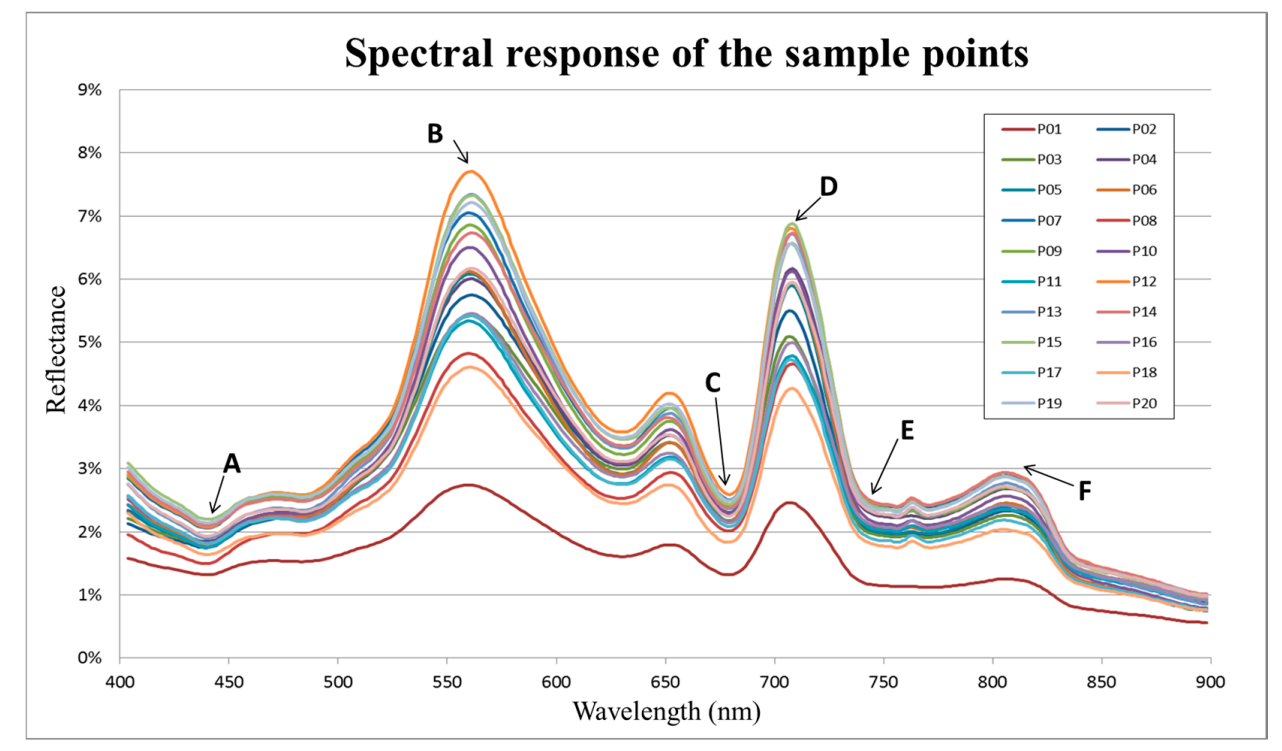

Figure 4. Spectral response of the sample points and the characteristic and identifiable spectral peaks of turbid productive waters indicated by the letters A, B, C, D, E and F.

By analyzing the curves, it is possible to note that, at all points, the spectral behavior of water was similar, as the main points of peaks and valleys in the graph remain the same wavelengths for all curves. There was only a small difference between the reflectance values of each point analyzed.

The spectral responses were quite similar to typical reflectance spectra collected in turbid productive waters. The reflectance is lower in the blue spectral range $400-500 \mathrm{~nm}$ (indicated by Letter A in Figure 4) and starts increasing at $500 \mathrm{~nm}$. In the green range, the reflectance was much higher, reaching a peak at about $560 \mathrm{~nm}$ (Letter B), caused by relatively less absorption of green wavelength by algae/chlorophyll. It is possible to observe the presence of a very steep valley in the curve in the red range, at approximately $680 \mathrm{~nm}$ (Letter C), where the curve of reflectance begins to increase. There is also a well-defined peak reflectance around $700 \mathrm{~nm}$ (Letter D), associated to the energy absorbed and back-scattered from water and phytoplankton. This high reflectance value 
decrease rapidly to about $750 \mathrm{~nm}$ (Letter E) and smoothly increases until $800 \mathrm{~nm}$ (Letter F) and, finally, decreases to about $900 \mathrm{~nm}$ [25-28].

Regarding the behavior of the spectral curves, it is emphasized that the results are consistent with those reported in the literature (Figure $5 \mathrm{a}-\mathrm{c}$ ), which presented the main features of the presence of chlorophyll in the lake.

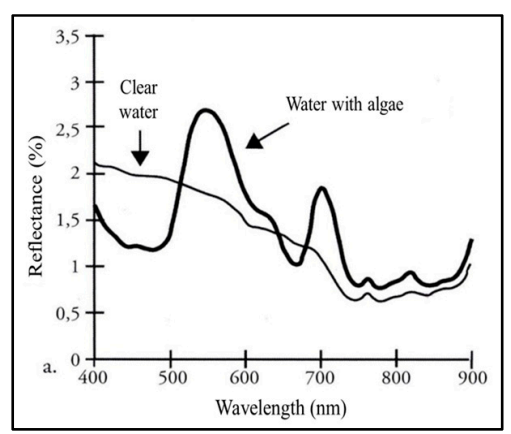

(a)

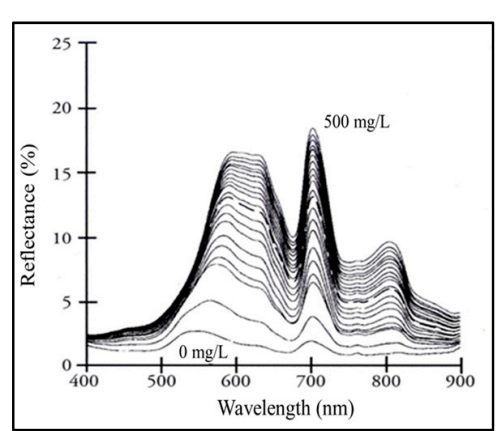

(b)

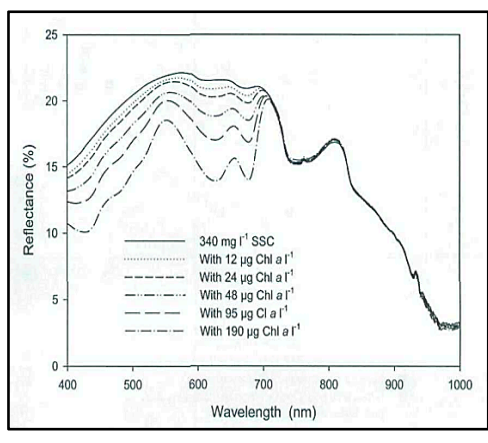

(c)

Figure 5. Behavior of the spectral curves reported in the literature: (a) comparison between clear water and water with algae [26]; (b) water rich in chlorophyll with variations of suspended solids concentrations [26]; (c) water rich in suspended solids with variations of chlorophyll concentrations [27].

Moreover, the graph (Figure 4) shows changes in the curve related to the other COAs. Low reflectance values in the blue range are caused by the presence of organic matter in the environment, and the small reflectance peak at $800 \mathrm{~nm}$ (Letter F) is characterized by the presence of suspended sediments in water.

After the behavioral analysis of the spectral reflectance curves, a study of the correlation between these data and the chlorophyll concentrations has been performed to establish a full mathematical model to quantify water chlorophyll from the spectral data collected in the field.

Aiming to reduce the errors associated with the statistical techniques used in this study, we chose to exclude the points with values obtained by water analysis considered outliers compared to others, which are points P11 and P14.

To study the correlations between the spectral data, we exclude the set of curves referring to Point P01. Such a situation is justified considering that problems with the spectral reading of this sample point were identified and that they were considered inconsistent with the other curves obtained. Thus, all the analyses presented here have been performed considering 17 sample points.

Several studies reported in the literature also used correlations considering the concentration of Chl-a and the spectral curve, spectral band ratios, or algorithms with more than two variables. The work conducted by Gitelson et al. [25] showed that the best results for Chl-a estimation in turbid productive inland waters were the two- and three-band models using wavelengths in the range from $670 \mathrm{~nm}$ to $675 \mathrm{~nm}$ (minimum reflectance in the red range), from $695 \mathrm{~nm}$ to $705 \mathrm{~nm}$ (NIR reflectance peak), and from $720 \mathrm{~nm}$ to $730 \mathrm{~nm}$ (minimum reflectance after NIR peak). Mishra and Mishra [28] predicted Chl-a concentration from remote sensing data using the normalized difference chlorophyll index (NDCI), following the concept of NDVI applied in vegetation monitoring, taking the spectral band difference at $708 \mathrm{~nm}$ and $665 \mathrm{~nm}$ and normalizing it by the sum of their reflectance.

Given the low correlations between this simple analysis, with $R^{2}$ inferior to 0.2 , we conducted a multivariate linear regression analysis between chlorophyll concentrations in the sample points (dependent variable) and two spectral band ratios (independent variables), which consider spectral points characteristic of Chl-a presence in water: $560 \mathrm{~nm}$ (green reflectance peak), $680 \mathrm{~nm}$ (reflectance minimum in the red range), and $708 \mathrm{~nm}$ (NIR reflectance peak). 
We considered as the analysis criteria to a confidence level of $95 \%$. As a result, we obtained the independent variables (Table 2) used to estimate the chlorophyll-a concentration and their respective coefficients in the equation.

Therefore, the determination of chlorophyll-a concentration through the two variables of the reflectance curve was obtained based on the equation shown below:

$$
\operatorname{Chl-a}(\mu \mathrm{g} / \mathrm{L})=\mathrm{I}+\mathrm{C}_{1}\left(R_{560} R_{680}^{-1}\right)+\mathrm{C}_{2}\left(R_{708} R_{680}^{-1}\right)
$$

Table 2. Analysis of the results of the multivariate linear regression.

\begin{tabular}{ccc}
\hline Variable & Coefficient & Value of Coefficient \\
\hline Intersection & $\mathrm{I}$ & -30.53 \\
$R_{560} R_{680}^{-1}$ & $\mathrm{C}_{1}$ & 6.05 \\
$R_{708} R_{680}^{-1}$ & $\mathrm{C}_{2}$ & -0.26 \\
\hline
\end{tabular}

This mathematical model returned a $R^{2}$ of 0.86 and a standard error of $5.12 \mu \mathrm{g} / \mathrm{L}$, indicating that the presence of chlorophyll-a in that environment is best explained by a set of variables.

From the obtained results, we highlight the importance of using in situ data collection tools such as spectroscopy to quickly determine parameters that infer water quality, providing a time and cost reduction with monitoring of water bodies.

\subsection{Correlation between NDVImod and Chlorophyll from Images Obtained with UAVS}

As a cartographic product obtained by the UAV flight and image processing, the orthorectified and georeferenced mosaic of the area is shown in Figure 6.

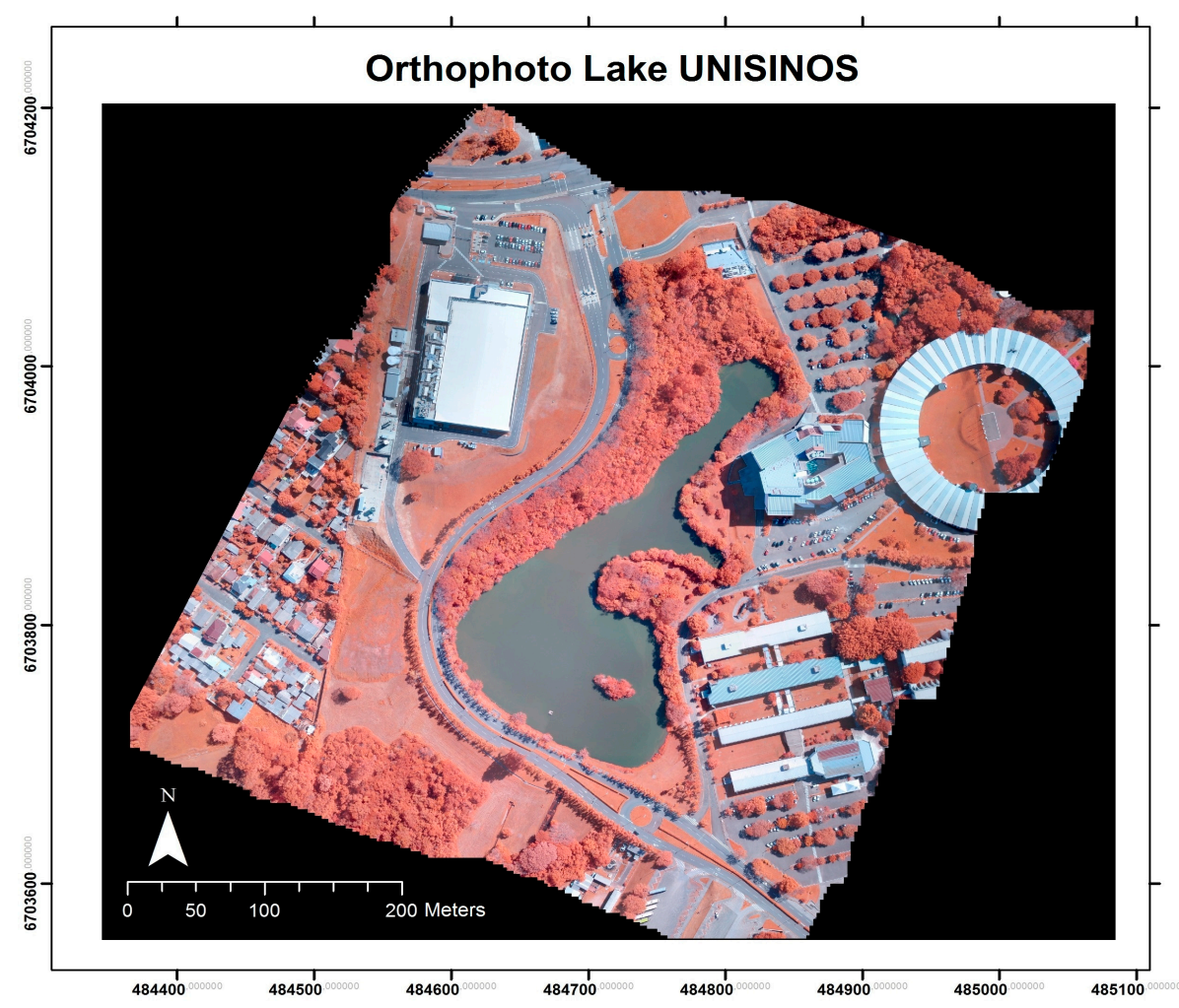

Figure 6. Georeferenced orthophoto of the lake. 
By an analysis of the orthophoto, it is possible to confirm that the image covered the entire area of study (lake) as well as a large area of its surroundings. The orthorectified mosaic served as the basis for the generation of the NDVImod image.

To improve the visualization of the spatial distribution of NDVImod in the lake, we first performed a clip of the study area only, which is shown in Figure 7a. Afterwards, we created a color composite image, shown in Figure $7 b$, which has been adjusted to highlight the differences between the index values.

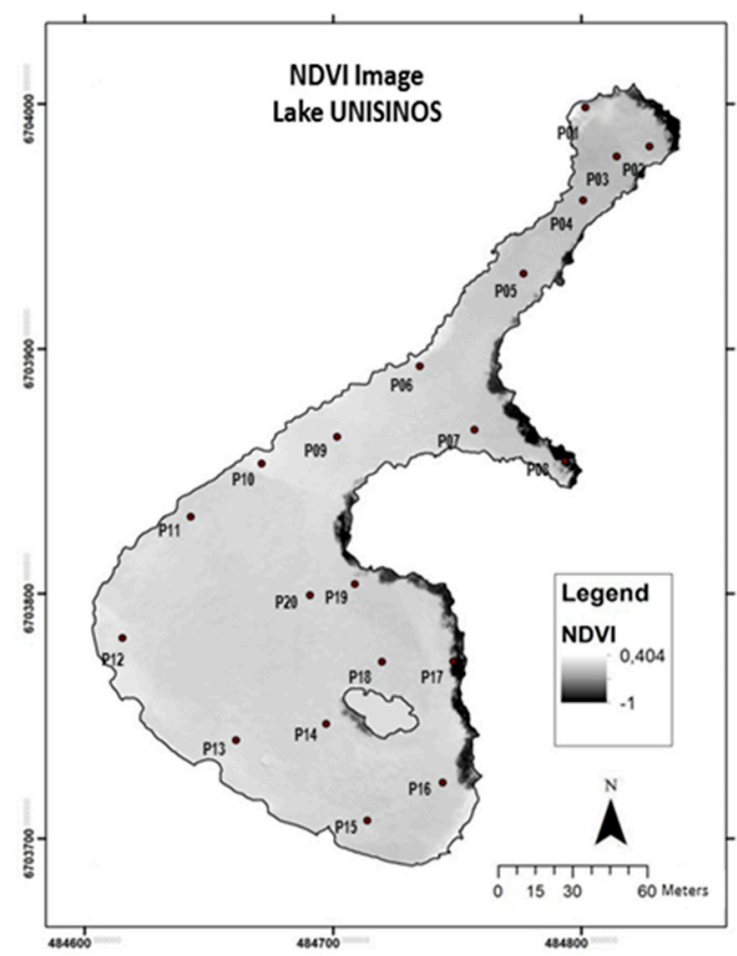

(a)

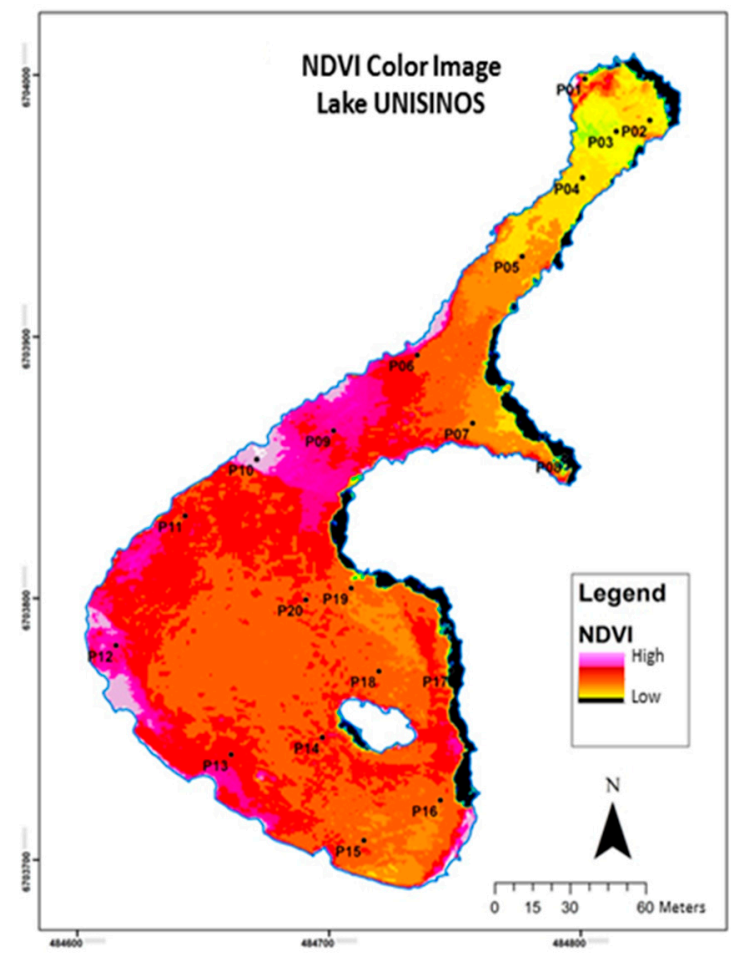

(b)

Figure 7. Modified normalized difference vegetation index (NDVImod) image of the lake section: (a) grayscale; (b) color composition.

It is worth noting that, during this stage, we realized that two sampling points established in the field were located in shaded areas of the image. Thus, we exclude these two points (P08 and P17) of the dataset from analysis, because their respective NDVImod values would not be representative of the water column.

Finally, we extracted the values for NDVImod in each pixel containing the sample point, and their values were used in the analysis of correlations with the chlorophyll-a concentration in the same spots. Table 3 shows the maximum and minimum NDVImod values obtained in this step as well as the average and standard deviation of the dataset.

Table 3. Average, maximum, minimum and standard deviation of NDVImod.

\begin{tabular}{cc}
\hline Parameter & Value NDVImod \\
\hline Minimum value/Location & $-0.1389(\mathrm{P} 02)$ \\
Maximum value/Location & $0.0493(\mathrm{P} 10)$ \\
Average & -0.0495 \\
Standard deviation & 0.0494 \\
\hline
\end{tabular}


For the correlation between the NDVImod data and the chlorophyll-a concentration in the water, we adopted stricter criteria for the selection of data, because the response of the sensor used in the images acquisition might have been affected by many factors, such as the reflection of solar radiation on the water surface, the interference of wind, and the atmosphere itself.

In addition to disregarding some of the sampling points previously mentioned and discussed, we also excluded from the dataset the NDVImod values outside the range (more or less) of the mean.

Considering these criteria, 10 remaining points have been used for the correlation analysis between the indices values and the chlorophyll-a concentration in the lake: P01, P05, P06, P07, P13, P15, P16, P18, P19, and P20.

The correlation model that had the best result was the curve of a second-order polynomial function (Figure 8), returning a correlation coefficient (r) of 0.71 , a $R^{2}$ equal to 0.51 and a standard deviation of $11.7 \mu \mathrm{g} / \mathrm{L}$.

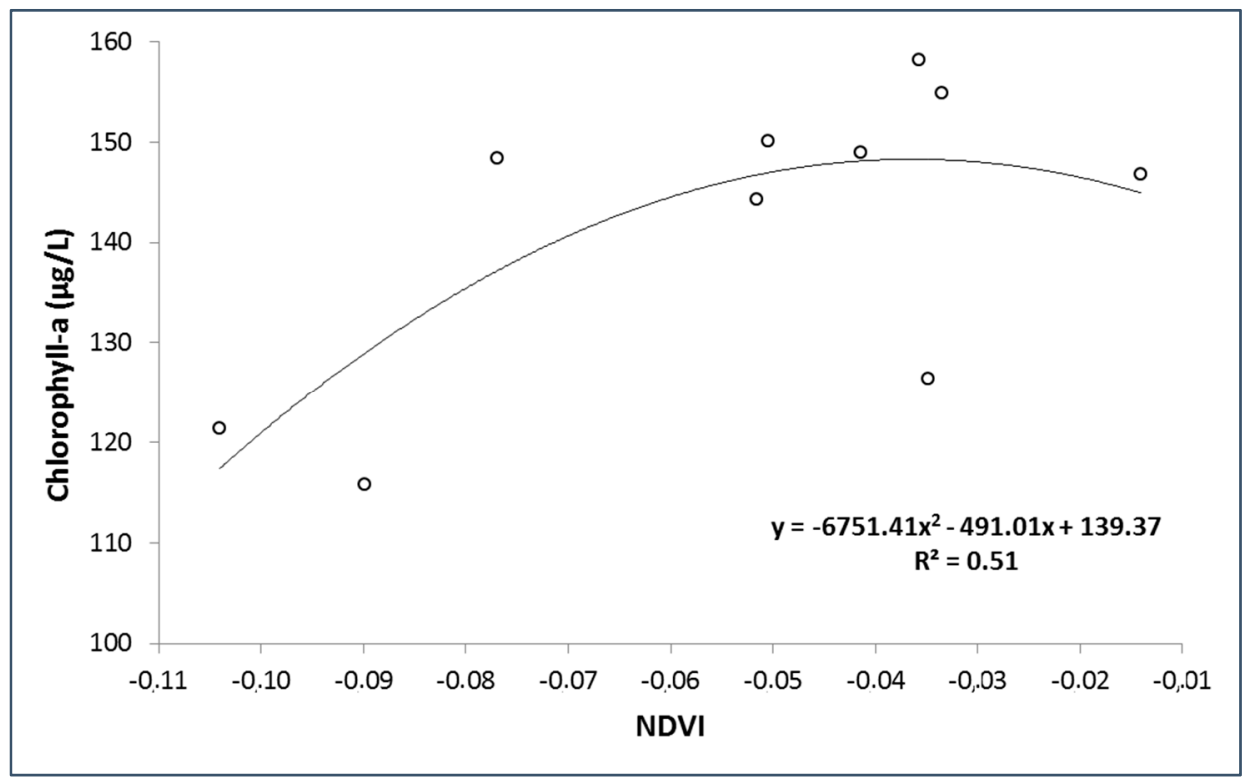

Figure 8. Relationship between concentration of Chl-a and NDVImod.

The polynomial equation adopted for the determination of chlorophyll-a in water bodies as a function of NDVImod is shown below:

$$
\text { Chl-a }(\mu \mathrm{g} / \mathrm{L})=139.37-491.01(\text { NDVImod })-6751.41\left(\text { NDVImod }^{2}\right) .
$$

Although the $R^{2}$ value obtained by this correlation was acceptable, there are not many studies in the literature that apply the NDVI in water bodies, and the few existing used it for area classification or used satellite images to do so. For example, the work of Nuhu [29] used the index to delimit areas of water (negative values), submerged aquatic vegetation (values around 0.15 ), and above water vegetation (greater than 0.15 ), without correlating to the presence of chlorophyll in water with the negative NDVI values.

Studies conducted by Londe [30] and Cândido et al. [19] indicated a strong linear relationship ( $R^{2}$ of 0.78 and 0.95 , respectively) between the NDVI values and chlorophyll concentration in water, which is not consistent with the findings of our study. However, the first author worked with fully eutrophic waters, reaching a concentration greater than $67,000 \mu \mathrm{g} / \mathrm{L}$ in their water samples, values that are extremely higher than those concentrations measured in the lake of study. The second authors used as study material two small water spring areas and Landsat satellite images, which could generate conflict in the interpretation of the index since the pixel value used could be suffering interference from 
local vegetation. Moreover, Lissner and Guasselli [31] did not obtain high coefficients of determination for NDVI and chlorophyll correlation $\left(R^{2}=0.02\right)$, possibly due to the low concentration of chlorophyll present in the study area (between 3 and $15 \mu \mathrm{g} / \mathrm{L}$ ) and the low spatial resolution of the images used to obtain the index (Landsat).

We emphasize that the high linear correlations in studies such as Londe [30] occur due to the better applicability of models based on NDVI for water with high contents of chlorophyll, as the response received by the sensor is similar to vegetation and the high homogeneity of the conditions of the study material being patterned according to the same main component present in the water (in this case, chlorophyll). An analysis of the chlorophyll in the laboratory of the same water sample showed a large amount of suspended inorganic solids in the studied lake, which explains the greater complexity in shaping this environment.

The use of UAVs in the mapping of these surfaces is notable for enabling centimetric resolutions of the study area, different from the satellite sensors, whose resolutions may be over $10 \mathrm{~m}$.

Among cases similar to the present study, which used the modified NDVI, none have been applied in water environments. However, the comparison is relevant in view of the wide applicability of new band arrangements, given that modified digital cameras (including the NIR band) increase the sensitivity of sensors to crop biomass [32,33] and that spectral indices using visible bands, when compared to NDVI and Green NDVI ( $(N I R-G) /(N I R+G))$, are more sensitive to leaf chlorophyll content than biomass [34]. Lehmann et al. [35], for example, used the same NDVImod to facilitate the distinction between healthy and infested trees, given the extreme low albedo ratio of dead biomass, which could be compared to the spectral characteristics of water bodies. Nijland et al. [36] also assessed vegetation health by using different variations of the NDVI. The red rejection band-pass NDVI (using the blue band instead of the red one) showed more variability than other indexes, demonstrating good sensitivity to spectral trends of vegetation. Rasmussen et al. [37] used the same modified camera and applied the NDVImod to assess the reliability of using consumer-grade cameras mounted on UAVs. The findings demonstrated that vegetation indices based on UAV imagery, similar to ground-based sensors and cameras, have capabilities of assessing crop responses. These studies demonstrate the applicability and reliability of modified NDVIs as an important tool for agriculture and other applications. The present study was a start for using this type of analysis in water environments.

\section{Conclusions}

The results of this research allow us to conclude that the two hypotheses were confirmed. It was possible to establish a correlation between the data for the chlorophyll-a concentration present in the lake of study and the responses obtained by the sensors used (NDVImod image generated through the UAV flight and spectral data obtained by the spectroradiometer).

Mathematical models were generated concerning these correlations, and they obtained satisfactory coefficients of determination $\left(R^{2}\right)$, namely, 0.86 by means of the mathematical model based on the multivariate correlation between the chlorophyll concentration in water and its spectral response and 0.51 using the correlation between NDVImod and chlorophyll present in the water by means of a second-order polynomial function.

It is worth mentioning that the models presented in this research have real values applicable only to the study material, and further analysis with larger amounts of samples from different locations would likely be needed to generalize the observed patterns.

The results can, however, serve as a starting point for further studies and deepen the study of the interference of other parameters in the response of sensors, such as water turbidity, the presence of suspended solids, lake depth, and background interference.

The models generated from this study confirm the applicability of data obtained by remote sensing in the management of water resources as quick tools for estimating variable concentrations, which assists in the constant monitoring of water bodies, and identifying the locations of critical points to undergo collections and more detailed analysis. 
Finally, it is emphasized that the application of alternative tools to continuously monitor aquatic environments is extremely important, given that preventive and/or corrective measures can be taken and socioeconomic impacts can be minimized or avoided.

Acknowledgments: This project was financially supported by the projects Modelagem Digital de Afloramentos utilizando GPU (MCT/FINEP-Pré-Sal Cooperativos ICT-Empresas 03/2010-Contract 01.23.4567.89). The second author thanks the Brazilian Council for Scientific and Technological Development (CNPq) for the research grant (Process 309399/2014-9).

Author Contributions: Tainá Guimarães, Mauricio Veronez, Leonardo Inocencio, Luiz Gonzaga Jr., and Fabiane Bordin were responsible for collecting and processing the spectral data and the images obtained from the UAV. Tainá Guimarães, Emilie Koste, Dalva Vitti, and Frederico Mauad were responsible for the water collection at the predetermined sampling points and for the laboratorial analysis. Marcelo Zagonel discussed the biological aspects involved in the laboratorial analysis. Tainá Guimarães, Emilie Koste, and Mauricio Veronez wrote the paper. Dalva Vitti, Ana Paula Larocca, and Frederico Mauad reviewed the paper. All the authors read and approved the paper final version.

Conflicts of Interest: The authors declare no conflict of interest.

\section{References}

1. Tundisi, J.G.; Tundisi, T.M. Limnologia, 1st ed.; Oficina de Textos: São Paulo, Brasil, 2008. (In Portuguese)

2. Sperling, M. Introdução à Qualidade das Águas e ao Tratamento de Esgotos, 3rd ed.; UFMG: Belo Horizonte, Brasil, 2005. (In Portuguese)

3. Smith, V.H.; Schindler, D.W. Eutrophication science: Where do we go from here? Trends Ecol. Evol. 2009, 24, 201-207. [CrossRef] [PubMed]

4. Wang, J.; Zhang, Y.; Yang, F.; Cao, X.; Bai, Z.; Zhu, J.; Chen, E.; Li, Y.; Ran, Y. Spatial and temporal variations of chlorophyll-a concentration from 2009 to 2012 in Poyang Lake, China. Environ. Earth Sci. 2015, 73, 4063-4075. [CrossRef]

5. Yu, Z.; Chen, X.; Zhou, B.; Tian, L.; Yuan, X.; Feng, L. Assessment of total suspended sediment concentrations in Poyang Lake using HJ-1A/1B CCD imagery. Chin. J. Oceanol. Limnol. 2012, 30, 295-304. [CrossRef]

6. Ritchie, J.C.; Zimba, P.V.; Everitt, J.H. Remote sensing techniques to assess water quality. Photogramm. Eng. Remote Sens. 2003, 69, 695-704. [CrossRef]

7. Walczykowski, P.; Jenerowicz, A.; Orych, A. A review on remote sensing methods of detecting physical water pollutants. Proc. Res. Conf. Tech. Discip. 2013, 1, 125-130.

8. Baban, S.M.J. Use of remote sensing and geographical information systems in developing lake management strategies. Hydrobiologia 1999, 395, 211-226. [CrossRef]

9. Zang, W.; Lin, J.; Wang, Y.; Tao, H. Investigating small-scale water pollution with UAV remote sensing technology. In Proceedings of the World Automation Congress (WAC) 2012, Puerto Vallarta, Mexico, 24-28 June 2012; IEEE: New York, NY, USA, 2012.

10. Tamminga, A.; Hugenholtz, C.; Eaton, B.; Lapointe, M. Hyperspatial remote sensing of channel reach morphology and hydraulic fish habitat using and unmanned aerial vehicle (UAV): A first assessment in the context of river research and management. Riv. Res. App. 2015, 31, 379-391. [CrossRef]

11. Su, T.-C.; Chou, H.-T. Application of Multispectral Sensors Carried on Unmanned Aerial Vehicle (UAV) to Trophic State Mapping of Small Reservoirs: A Case Study of Tain-Pu Reservoir in Kinmen, Taiwan. Remote Sens. 2015, 7, 10078-10097. [CrossRef]

12. Cândido, A.K.A.A.; Paranhos Filho, A.C.; Haupenthal, M.R.; Silva, N.M.; Correa, J.S.; Ribeiro, M.L. Water quality and chlorophyll measurement through vegetation indices generated from orbital and suborbital images. Water Air Soil. Pollut. 2016. [CrossRef]

13. Toth, C.; Józków, G. Remote sensing platforms and sensors: A survey. ISPRS J. Photogam. Remote Sens. 2016, 115, 22-36. [CrossRef]

14. Colomina, I.; Molina, P. Unmanned aerial systems for photogrammetry and remote sensing: A review. ISPRS J. Photog. Remote Sens. 2014, 92, 79-97. [CrossRef]

15. Colomina, I.; Blázquez, P.; Molina, P.; Parés, M.E.; Wis, M. Towards a New Paradigm for High-Resolution Low-Cost Photogrammetry and Remote Sensing. Available online: http:/ /www.isprs.org/proceedings / XXXVII/congress/1_pdf/205.pdf (accessed on 1 March 2017). 
16. Ballesteros, R.; Ortega, J.F.; Hernández, D.; Moreno, M.A. Applications of georeferenced high-resolution images obtained with unmanned aerial vehicles. Part I: Description of image acquisition and processing. Precis. Agric. 2014, 15, 579-592. [CrossRef]

17. Flynn, K.F.; Chapra, S.C. Remote Sensing of Submerged Aquatic Vegetation in a Shallow Non-Turbid River Using an Unmanned Aerial Vehicle. Remote Sens. 2014, 6, 12815-12836. [CrossRef]

18. Luo, J.; Li, X.; Ma, R.; Li, F.; Duan, H.; Hu, W.; Qin, B.; Huang, W. Applying remote sensing techniques to monitoring seasonal and interannual changes of aquatic vegetation in Taihu Lake, China. Ecol. Ind. 2016, 60, 503-513. [CrossRef]

19. Tauro, F.; Oliveri, G.; Petroselli, A.; Porfiri, M. Flow monitoring with a camera: A case study on a flood event in Tiber River. Envrion. Monit. Assess. 2016. [CrossRef] [PubMed]

20. Honkavaara, E.; Saari, H.; Kaivosoja, J.; Pölönen, I.; Hakala, T.; Litkey, P.; Mäkynen, J.; Pesonen, L. Processing and Assessment of Spectrometric, Stereoscopic Imagery Collected Using a Lightweight UAV Spectral Camera for Precision Agriculture. Remot. Sens. 2013, 5, 5006-5039. [CrossRef]

21. Moraes, E.E.; Sampaio, M.I.R; Garcia, V.Q.; Severo, P.T.G.; Alonso, M.; Guimarães, L.G.; Pereira, R.S. Análise da resposta espectral da água em estações de tratamento para comprimentos de onda dentro do visível. In Proceedings of the XIV Simpósio Brasileiro de Sensoriamento Remoto, SBSR, Natal/RN, Brasil, 25-30 April 2009. (In Portuguese)

22. Cheng, C.; Wei, Y.; Sun, X.; Zhou, Y. Estimation of chlorophyll-a concentration in turbid lake using spectral smoothing and derivative analysis. Int. J. Environ. Res. Public Health 2013, 10, 2979-2994. [CrossRef] [PubMed]

23. Murugan, P.; Sivakumar, R.; Pandiyan, R.; Annadurai, M. Comparison of in-Situ Hyperspectral and Landsat ETM+ Data for Chlorophyll-a Mapping in Case-II Water (Krishnarajapuram Lake, Bangalore). J. Indian Soc. Remote Sens. 2016, 44, 949-957. [CrossRef]

24. Nusch, E.A. Comparisonof different methods for chlorophyll and phaeopigments determination. Arch. Hydrobiol. 1980, 14, 14-36.

25. Gitelson, A.A.; Schalles, J.F.; Hladik, C.M. Remote chlorophyll-a retrieval in turbid, productive estuaries: Chesapeake Bay case study. Remote Sens. Environ. 2007, 109, 464-472. [CrossRef]

26. Jensen, J.R. Sensoriamento Remoto do Ambiente: Uma Perspectiva em Recursos Terrestres; Parêntese: São José dos Campos, Brasil, 2011. (In Portuguese)

27. Sváb, E.; Tyler, A.N.; Preston, T.; Présing, M.; Balogh, K.V. Characterizing the spectral reflectance of algae in lake Waters with high suspended sediment concentrations. Int. J. Remote Sens. 2005, 26, 919-928. [CrossRef]

28. Mishra, S.; Mishra, D.R. Normalized difference chlorophyll index: A novel model for remote estimation of chlorophyll-a concentration in turbid productive waters. Remote Sens. Environ. 2012, 117, 394-406. [CrossRef]

29. Nuhu, M.R. Delineation and Quantification of Submerged Aquatic Vegetation (SAV) in Inland Lakes Using Multispectral Sensors. Master's Thesis, University of Twente, Enschede, The Netherlands, February 2016.

30. Londe, L.R. Comportamento Espectral do Fitoplâncton de um Reservatório Brasileiro Eutrofizado-Ibitinga (SP); Doutorado em Sensoriamento Remoto, Instituto Nacional de Pesquisas Espaciais: São José dos Campos, Brazil, 2008. (In Portuguese)

31. Lissner, J.B.; Guasselli, L.A. Variations of the normalized difference vegetation index (NDVI) in the Itapeva-RS Lake, north coast of Rio Grande do Sul, Brazil, from temporal series analysis. Soc. Nat. 2013, 25, 427-440. [CrossRef]

32. Hunt, E.R.; Hively, W.D.; Fujikawa, S.J.; Linden, D.S.; Daughtry, C.S.T.; McCarty, G.W. Acquisition of NIR-green-blue digital photographs from unmanned aircraft for crop monitoring. Remote Sens. 2010, 2, 290-305. [CrossRef]

33. Hunt, E.R.; Hively, W.D.; McCarty, G.W.; Daughtry, C.S.T.; Forrestal, P.J.; Kratochvil, R.J.; Carr, J.L.; Allen, N.F.; Fox-Rabinovitz, J.R.; Miller, C.D. NIR-green-blue high-resolution digital images for assessment of winter cover crop biomass. GISci. Remote Sens. 2011, 48, 86-98. [CrossRef]

34. Hunt, E.R.; Daughtry, C.S.T.; Mirsky, S.B.; Hively, W.D. Remote Sensing With Simulated Unmanned Aircraft Imagery for Precision Agriculture Applications. IEEE J. Sel. Top. App. Earth Obs. Remote Sens. 2014, 7, 4566-4571. [CrossRef]

35. Lehmann, J.R.K.; Nieberding, F.; Prinz, T.; Knoth, C. Analysis of Unmanned Aerial System-Based CIR Images in Forestry-A New Perspective to Monitor Pest Infestation Levels. Forests 2015, 6, 594-612. [CrossRef] 
36. Nijland, W.; Jong, R.; Jong, S.M.; Wulder, M.A.; Bater, C.W.; Coops, N.C. Monitoring plant condition and phenology using infrared sensitive consumer grade digital cameras. Agric. For. Met. 2014, 184, 98-106. [CrossRef]

37. Rasmussen, J.; Ntakos, G.; Nielsen, J.; Svensgaard, J.; Poulsen, R.; Christensen, S. Are vegetation indices derived from consumer-grade cameras mounted on UAVs sufficiently reliable for assessing experimental plots? Eur. J. Agric. 2016, 74, 75-92. [CrossRef] 